\title{
A MULTIREGIONAL PLANNING AND FORECASTING MODEL WITH SPECIAL REGARD TO THE PUBLIC SECTOR
}

F. Snickars

International Institute for Applied Systems Analysis, Laxenburg, A ustria

A. Granholm

Stockholm Regional Planning Office, Stockholm, Sweden

RR-82-21

May 1982

Reprinted from Regional Science and Urban Economics, volume 11(1981)

INTERNATIONAL INSTITUTE FOR APPLIED SYSTEMS ANALYSIS

Laxenburg, Austria 
Research Reports, which record research conducted at IIASA, are independently reviewed before publication. However, the views and opinions they express are not necessarily those of the Institute or the National Member Organizations that support it.

Reprinted with permission from Regional Science and Urban Economics 11: 377-404, 1981. Copyright $\odot 1981$ North-Holland Publishing Company.

All rights reserved. No part of this publication may be reproduced or transmitted in any form or by any means, electronic or mechanical, including photocopy, recording, or any information storage or retrieval system, without permission in writing from the copyright holder. 


\section{FOREWORD}

This report deals with a multiregional economic model that places special emphasis on the public sector. However, rather than treating this part of the economic system in an aggregated way, it disaggregates public activity considerably, and retains the distinction between social and economic overhead capital. Besides treating the political targets for regional equity explicitly, the model also contains relations that simulate the influence of public capital on private-sector productivity.

Earlier research on economic models has usually made a strict distinction between predictive and planning models. However, this report gives an example of a model that can be used for both purposes. Thus, it is typical of a recent generation of regional economic models for policy evaluation.

The model in this report was developed partly in Sweden and partly under the auspices of the Regional Development group at the International Institute for Applied Systems Analysis. At the Institute it has been used in the regional analysis for physical planning in southwest Skane, Sweden, one of the applied research activities of the Regional Development group. However, this report gives a general treatment of the model without reference to the case studies.

BORIS ISSAEV 


\title{
A MULTIREgiONAL PLANNING AND FORECASTING MODEL WITH SPECIAL REGARD TO THE PUBLIC SECTOR*
}

\author{
F. SNICKARS \\ International Institute for Applied Systems Analysis, A-2361, Laxenburg, Austria
}

\section{A. GRANHOLM}

Stockholm Regional Planning Office, Fack S-10450, Stockholm, Sweden

\begin{abstract}
Despite the magnitude of the public sector and its rapid growth most multiregional economic models are lacking public sector content. The present paper aims at incorporating some of the roles of the public sector in the regional development. It is done within the framework of a multiregional optimization model for the allocation of private and public investment, production, employment (and population) over economic sectors and regions. By choosing appropriate objective functions, the model may be used for either planning or forecasting purposes. In the model the focus is on the public sector as a service and provision body and as a provider of public infrastructure. Its role as an agent for transfer payments is not stressed. The capacities of the model are illustrated by means of an example concerning Swedish regional development $1977-1983$.
\end{abstract}

\section{Conceptual background}

Despite the magnitude of the public sector and its rapid growth, at least in so called mixed economies, most interregional and regional economic models are void of public sector content. In contrast, the industrial sectors are often analyzed in great detail even though the determinants of their development may lie in world-scale market and technological change factors. If treated at all, the public sector is usually seen as an essentially homogeneous entity, its development being exogenously given and with crude relations to the rest of the economy.

The present paper has as its fundamental aim an attempt to illustrate how a somewhat more balanced treatment of the various sectors of the economy can be undertaken. Instead of concentrating on private sector costs and benefits we want to include both private and public costs and benefits of different patterns of resource allocation.

The incorporation of a multidimensional public sector implies a need for the economic analysis to be outspokenly multiregional. This is especially

\footnotetext{
*Views or opinions expressed herein do not necessarily represent those of the Institute or of its National Member Organizations.
}

0166-0462/81/0000-0000/\$02.50 (C) 1981 North-Holland 
important in a country like Sweden with its large and sparsely populated rural areas and widely dispersed urban areas. In contrast to many industrial sectors which, as mentioned, have national or even international markets, both the public and the private service sectors are primarily of regional and local character. The fact that the public sector expansion tends to strengthen the regional and local character of the total economy is an important observation to be represented in any meaningful regional economic analysis.

A focus on public sector problems may give rise to confusion in comparisons between organizational settings in various countries. What is public in some countries is private in others. Even in planned economies a distinction is made between so called productive and non-productive activities. Here, we will use a broad interpretation of the public sector, not going into arguments whether one or other industrial branch is public or private. Furthermore, we will not stress the interpretation of the public sector as a producer of public goods. Our public sector does more than that and we pragmatically wish to see it as an entity performing the public activities typical for mixed Western European economies.

A categorization of those activities may contain at least the following four items:

- fulfilling regional demands for public services (population orientation),

- acting as a producer of locations (population and production system orientation),

- increasing the overall productivity of the economy (production system orientation),

- acting as a bureaucratic multi-level organization (planning and control orientation).

In this paper we will present a multiregional optimization model for the allocation of private and public investment, production, employment and population over economic sectors and regions. ${ }^{1}$ One aim of this modelling work is to investigate some of the connections mentioned above between the private and public sectors. The focus will be on these interactions and the relations within the regional production systems will be kept simple.

Another aim is to formulate the model in a way which is used in a major part of regional economic policy and employment policy discussions, at least in Sweden. Thus, we wish to model a large number of linkages between different parts of the economic system in a simple way rather than modelling a few links in a complex way.

\section{Theoretical background and general structure}

There is a considerable literature on multiregional economic models. The field has expanded quite rapidly during the 1970 s along at least three paths:

\footnotetext{
${ }^{1} \mathrm{~A}$ more detailed description of the model structure is given in Granholm (1981).
} 
- interregional input-output models,

- multiregional programming models,

- multiregional econometric models.

Among recent interregional input-output models we may mention Polenske (1972), Carlberg (1979) and Los (1980). The interregional dynamic input-output models of Andersson and Persson (1980) and Martellato (1980) exhibit examples of an elaborate treatment of interregional linkages, estimated for instance by information-theoretic principles, see also Snickars (1978) and Batten (1980).

In the models mentioned above the treatment of supply constraints and other regional and sectoral restrictions is weak. The multiregional programming modellers have loosened several of these restrictive assumptions, incorporating the input-output relationships among a set of general linear restrictions. These constraints normally represent balance relations among production factor stocks, capital utilization levels, international trade claims, etc. Optimal development paths are then traced out using alternative objectives, see e.g., Rietveld (1980) or Lundqvist (1980). A Swedish line of research originating in the work of Tinbergen in the $1960 \mathrm{~s}$ on multilevel planning models goes from Mennes, Tinbergen and Waardenburg (1969), via Granholm and Ohlsson (1975), Snickars and Lundqvist (1978), and Karlqvist, Sharpe, Batten and Brotchie (1978) to the current paper. In all these models the problem of national efficiency versus regional equity is tackled by optimizing investment or other cost functions as proxies for consumption maximization.

In the above school of models, econometrically established causal relationships do not play a significant role, the exception being the methods for estimating interregional input-output tables. In a sense one can see an econometric model as a reduced form of a general input-output model, although generally no such under-lying causal structure is assumed. The most full-fledged recent multiregional economic models, Courbis and Cornilleau (1978), Courbis (1979), Thys-Clement, van Rompuy and de Corel (1979), contain both input-output structures, econometrically estimated demand and supply functions, income formation mechanisms and migration. Large scale systems of econometric relations form the core of the regional policy evaluation models of Treytz (1980) and Ballard and Wendling (1980), both developed for the American economy.

Although some of these models contain government expenditures none of the models mentioned above is very elaborate as regards the public sector. Therefore, the current model, simple as it is, should provide an example of a more elaborate treatment of the public sector not only as a demand sink but also as a supply source in regional development processes.

In the model the interregional allocation of industrial production is 
assumed to be determined chiefly by interregional productivity differentials, whereas the service sectors are located according to demand requirements related to the magnitude of various target groups among the regional populations. The demand-supply relationships are expressed by fixed, minimum requirement ratios between the relevant sectors and population groups.

Such minimum requirements have also been introduced to specify technical relationships between the volume of infrastructural capital and the capital of the private sector. The aim is to guarantee that the public infrastructure in each region is large enough to adequately maintain the level of productivity and factor proportions in the (private) sectors.

A disaggregation of the public sector calls for an endogenous treatment of the regional population development. The common assumption in other models is to make exogenous population forecasts, thus motivating a treatment of the whole public sector as exogenous.

The treatment of intersectoral and interregional linkages in the model is rather weak. The model is not intended to treat interregional trade explicitly. Instead, the idea is that a projected distribution of production and employment over regions will give rise to an adjustment of existing interregional shipment patterns. This is the same assumption as is often used for commuting in urban land-use models, see Lundqvist (1977) or Williams and Senior (1977).

\section{The structure of the model}

\subsection{Regions and sectors}

In the model, called REGAL below, the regional dimension of the Swedish economy is analyzed from a macroeconomic point of view. The regional disaggregation may be varied between applications. So far the model has been developed, employing a subdivision of Sweden into eight more or less functional regions. In fig. 1 these eight regions are listed and mapped together with their 1977 population figures.

While the regional level of aggregation may be varied in the model the sectoral subdivision is more rigid. It is based on a grouping of sectors according to their properties of interregional immobility versus mobility. The total economy is divided into 21 sectors of which six are allocated over regions on exogenous grounds. In table 1 the sectors are grouped into main groups, in which the 1977 labour force sizes are included as background information. It should be observed that in some cases the only sector characteristic is its capital stock while the corresponding labour is accounted for under another heading.

Thus, the employment in the housing sector is accounted for in sector 4, private services, while all labour in construction is collected in the 


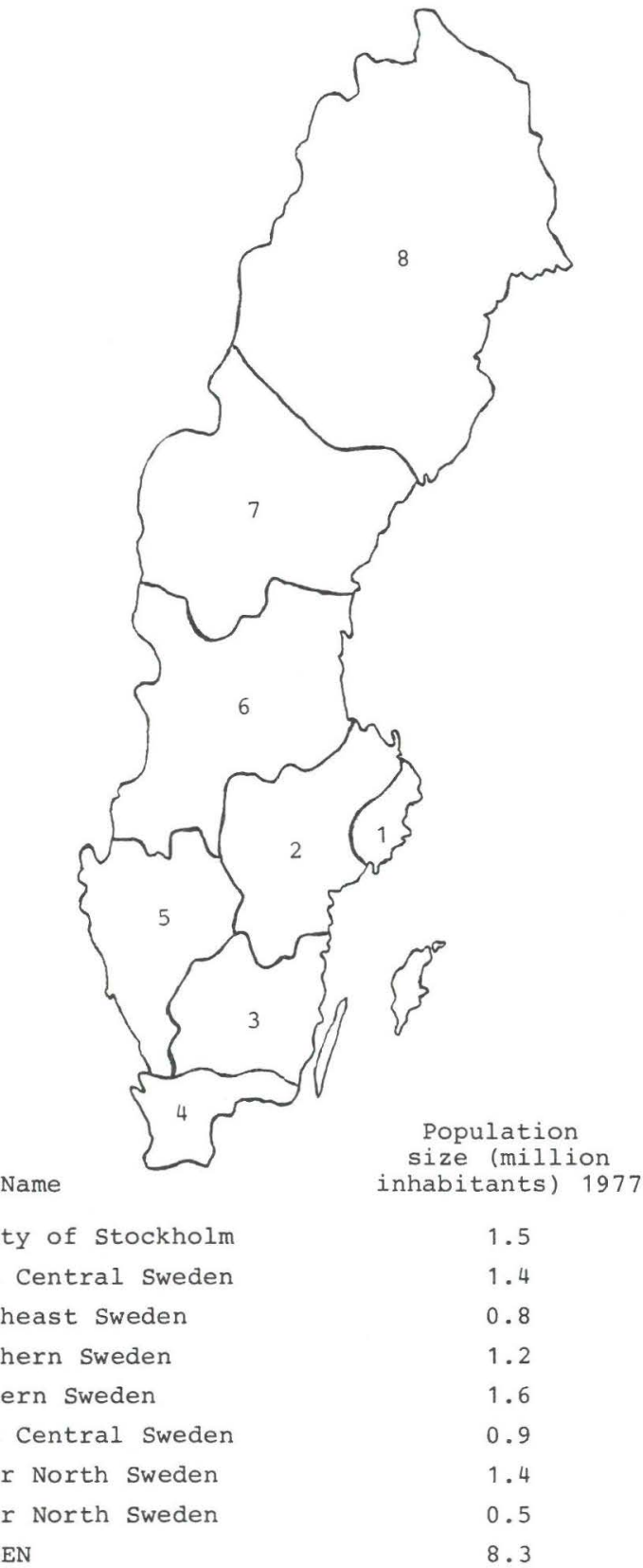

Fig. 1. Regional subdivision of Sweden. 
Table 1

Sectoral subdivision of the Swedish economy.

\begin{tabular}{|c|c|c|}
\hline No. & Name & $\begin{array}{l}\text { Employment } 1977 \\
\text { (millions) }\end{array}$ \\
\hline \multicolumn{2}{|c|}{ Regional and local services } & \multirow[t]{6}{*}{2.2} \\
\hline (1) & Child care and basic education & \\
\hline (2) & Medical services and care for the aged & \\
\hline (3) & Regional and local public administration & \\
\hline (4) & Private services (trade, banking, business services) & \\
\hline (5) & Transport and communication & \\
\hline \multicolumn{2}{|c|}{ Industry } & \multirow[t]{8}{*}{1.0} \\
\hline (6) & Food manufacturing & \\
\hline (7) & Textile and leather industry & \\
\hline (8) & Manufacture of wood and paper products, printing & \\
\hline (9) & Chemical industry & \\
\hline (10) & Basic metal works & \\
\hline (11) & Manufacture of machinery and equipment & \\
\hline (12) & Other industry products & \\
\hline \multicolumn{2}{|c|}{ Capital intensive infrastructure and construction } & \multirow[t]{4}{*}{0.3} \\
\hline (13) & Housing stock & \\
\hline (14) & Electricity and water production & \\
\hline (15) & Construction industry & \\
\hline \multicolumn{2}{|c|}{ Exogenously allocated sectors } & \multirow[t]{7}{*}{0.5} \\
\hline (16) & National private services & \\
\hline (17) & National public administration & \\
\hline (18) & Agriculture and forestry & \\
\hline (19) & Mining and quarrying & \\
\hline (20) & Manufacture of non-metallic mineral products (stone) & \\
\hline (21) & Road capital & \\
\hline \multicolumn{2}{|c|}{ Population } & \multirow[t]{2}{*}{8.3} \\
\hline (22) & Regional population level & \\
\hline
\end{tabular}

construction sector, number 15 . The employment in road maintenance is included in sector 5, transport and communication, while the labour used in road construction is of course accounted for in sector 15 .

Compared to other similar planning models, the public sector has been disaggregated to a relatively high degree in the REGAL model. There are five public administration sectors of which three are endogenously allocated in the model. This disaggregation is necessary in order to separate different target groups (children, old people) and their demand for public services. The regional dimension also forces us to distinguish between those public sectors which are interregionally mobile and those which are not.

The distinction between different degrees of interregional mobility is characteristic also for the disaggregation of the private sectors. Agriculture, 
mining and non-metallic mineral products are assumed to be interregionally immobile, but at the same time not markedly dependent on local demand. Consequently, they have been treated exogenously which is also the case with the road sector.

In the following sections we shall give a description of the structure of the model, starting with the various kinds of restrictions to be satisfied within the model by permitted changes in regional investments, capital stocks, production levels and employment. We shall thereby collect the restrictions into subgroups with internal similarities. Finally, we shall discuss alternative objective functions for discriminating among permitted regional development trajectories.

The notations needed for the formula exposition are explained in appendix 1 . We use the letter $i$ as sectoral and $k$ as regional subindex. The sectors are listed in table 1 . There are $m$ sectors and $n$ regions. Since the model is comparative-static in the current version the time dimension will be suppressed.

The restrictions of the model consist of three fundamental types. There is a set of technology descriptions where the economy is characterized in a linear fashion. Production is measured in terms of value added and an assumption is made that input-output relations do not vary over regions. Thus, inputoutput relationships are not included in the framework at this stage but treated in a separate section.

Another type of restriction is provided by forecast production levels in nationally mobile industrial sectors. The introduction of national production targets in service and public sectors has been made optional in the model. A basic idea of the model in this respect is that supply-demand relationships in all sectors should be formulated at the regional level, where balancing actually occurs.

A third group of restrictions is provided by basically politically determined regional demand-supply restrictions. By varying the minimum requirement standards of these restrictions, investment cost consequences of changed ambitions in regional policy making may be traced out.

\subsection{Technological relations and restrictions}

The relations below all apply to the time-point under study, i.e., parameter trend expressions are not stated explicitly,

$$
\begin{aligned}
& Q_{i}^{k}=\xi_{i}^{k} C_{i}^{k}, \\
& Q_{i}^{k}=\eta_{i}^{k} L_{i}^{k}, \\
& C_{i}^{k}=\lambda_{i}^{k} L_{i}^{k} \quad \text { where } \lambda_{i}^{k}=\eta_{i}^{k} / \xi_{i}^{k},
\end{aligned}
$$




$$
\begin{aligned}
& C_{i}^{k}=\delta_{i}^{k} C_{0 i}^{k}+I_{i}^{k}, \\
& I_{i}^{k} \geqq 0 .
\end{aligned}
$$

Eqs. (1) and (2) provide the linear relationships between sector output and factor inputs. It should be observed that the above description implies an implicit assumption of full (or fixed) utilization of the capital stock in each sector and region. The productivity differences between the regions are not always reflected through the output-capital and output-labour ratios differences in scale and in product composition can disturb the picture.

A special relation is introduced in the model to define the level of employment in the building and construction sector. Since the investments in (4) comprise all investments over a (say, 6-year) period of time while the employment variable measures the activity level in the horizon year, an assumption must be made to relate the two entities involved,

$$
L_{15}^{k}=\frac{1}{\lambda_{15}^{k} T} \sum_{i=1}^{21} \mu_{i} I_{i}^{k} .
$$

In (6) $T$ stands for the length of the planning period. Since the investment variable in (6) includes both machinery and building investments there is a need to crudely single out the part of total investments that generates demand for construction labour. ${ }^{2}$

In the model an attempt has been made to tie the level of technical and social public infrastructure to the capital stock in the private sectors, approximating the economic level of the region (observe that each region is assigned its own characteristic $v$-parameter, calibrated in a nationally uniform way in order to adapt to national volume targets),

$$
\begin{aligned}
& C_{1}^{k}+C_{2}^{k}+C_{3}^{k} \geqq v_{123}^{k}\left[\sum_{i \in I_{\mathrm{pr}}} C_{i}^{k}+C_{13}^{k}\right], \\
& C_{5}^{k}+C_{21}^{k} \geqq v_{5,21}^{k}\left[\sum_{i \in I_{\mathrm{pr}}} C_{i}^{k}+C_{13}^{k}\right], \\
& C_{14}^{k} \geqq v_{14}^{k}\left[\sum_{i \in I_{\mathrm{pr}}} C_{i}^{k}+C_{13}^{k}\right] .
\end{aligned}
$$

In (7)-(9) $v_{j}^{k}$ are minimum requirement parameters estimated from historical capital stock data. The subset of private sectors is complemented by the housing sector.

${ }^{2} \mathrm{~A}$ similar linking technique was also practised in a dynamic input-output model of the Stockholm economy, see Ohlsson, Granholm et al. (1972). 
These expressions represent weak specifications of technology sets for public infrastructure and private capital inputs. If looked upon from a production function perspective, the relations imply that several private production sectors share the same public infrastructure goods as inputs to their production processes. The degree of publicness of the infrastructure in question should determine at what regional and sectoral level the balance claims (7)-(9) are formulated.

Some difficulties are thus connected with the choice of regional level and what sectors to relate to the volume of infrastructure provided. Almost all sectors not included in the infrastructure ones are here seen as benefiting from the infrastructure. The claim implies that any private sector investment, ceteris paribus, creates a need for complementary public infrastructure investment. However, technical progress is introduced in the minimum requirement parameters.

\subsection{Forecasted national and regional restrictions}

The current regional planning model should be used in conjunction with national economic forecasting models. It could be used as a means of consistency checks as well as for conditional regional forecasting purposes.

$$
\begin{aligned}
& \sum_{k=1}^{n} L_{i}^{k} \geqq \bar{L}_{i}, \quad i=1, \ldots, 5,15, \ldots, 17, \\
& \sum_{k=1}^{n} Q_{i}^{k} \geqq \bar{Q}, \quad i=4, \ldots, 16,18-20, \\
& \sum_{k=1}^{n} C_{i}^{k} \geqq \bar{C}_{i}, \quad i=13,14,21, \\
& \sum_{k=1}^{n} P^{k} \geqq \bar{P} .
\end{aligned}
$$

The nature of the national targets differs between sectors. For the industrial sectors the national production targets are indispensable for the chosen allocation mechanism, since the model optimizes the regional allocation given the national (sector) forecasts. These forecasts are expressions of the conditions in the national and international markets.

The national targets for the other sectors do not play the same crucial role and may often be dispensed with. In some cases they may play a political role, for example the national volume of housing construction, and the cost effects in a regional perspective of such national targets can be illustrated by 
the model.

$$
\begin{aligned}
& \underline{P}^{k}<P^{k} \leqq \bar{P}^{k}, \\
& \underline{\rho}^{k} P^{k} \leqq L^{k} \leqq \bar{\rho}^{k} P^{k}, \\
& P^{k}=\Psi^{k} P_{0}^{k}+M^{k}-U^{k} .
\end{aligned}
$$

Both population and labour force are treated as variables in this model. Because of the linear technology assumptions, it may be necessary to limit the range of these variables within restrictions. Observe that condition (5) above is a guarantee, $\underline{L}_{i}^{k}$, that sectoral levels of employment do not decrease too rapidly leading to unacceptable social costs. Relation (16) is an example of a possible treatment of migration flows in the model. In fact, a more detailed treatment of the population development would not be difficult to achieve (age structure, multiregional migration flows).

\subsection{Demand and supply of regional services}

Some of the restrictions included under the above heading, e.g., the ones giving frames of future regional populations, have a clear political significance. The simple treatment of public services given here has also been inspired by political statements. In discussions of public service levels it is common to use access measures where the supply of a certain public service is related to some subgroup of the population, defined as the target group. We have simply operationalized some of these measures and introduced them as minimum requirements. ${ }^{3}$ Other restrictions in this group are direct supplydemand balance restrictions,

$$
\begin{aligned}
& L_{1}^{k} \geqq v_{1}^{k} \sum_{i=1}^{21} \phi_{i}^{k} L_{i}^{k}, \\
& L_{1}^{k} \geqq \sigma_{1}^{k} \beta^{k} P^{k}, \\
& L_{2}^{k} \geqq \sigma_{2}^{k} \gamma^{k} P^{k}, \\
& L_{3}^{k} \geqq \sigma_{3}^{k} P^{k}, \\
& L_{4}^{k} \geqq \sigma_{4}^{k} L^{k}, \\
& L_{5}^{k} \geqq \sigma_{5}^{k} L^{k}, \\
& C_{13}^{k} \geqq \sigma_{13}^{k} \varepsilon^{k} P^{k} .
\end{aligned}
$$

${ }^{3}$ We disregard the effect of commuting here. 
As can be seen from the expressions above we have chosen different target groups for the demand of the various services. The demand for private service is often supposed to depend on the regional income level, but we have chosen total employment as proxy for income. The child care sector is linked both with the labour (17) and population (18) variables. The reason is the close connection between the demand for child care and the increasing participation rate of women.

The expression (23) for the demand for dwellings is of considerable importance in determining the level of the regional population. Here it is justifiable to talk of an active effect from the public to the private sector, in this case in creating housing services for an expanding population. We have assumed that the $\sigma$-parameters, denoting the (inverse) population density, follow the national development trend. In reality the density may be more elastic, allowing for temporary deviations in density as the economic activity rises or falls, reflecting the more tardy movements of the volume of new housing construction.

\subsection{Input-output relationships}

In the exposition of the model so far we have not referred explicitly to the intersectoral relationships within and between regions. One reason for this is that we wish to keep the model as simple as possible as regards the internal structure of the private production system. This section will be devoted to a presentation of the commodity balances as well as to a discussion about income formation and distribution aspects. The section thus treats the fourth role of the public sector, i.e., its function as an agency for income transfers.

We assume that the basic supply-demand balances of production are formulated as follows:

$$
\begin{array}{ll}
X_{i}^{k}+\mu n_{i}^{k} X_{i}^{k}+\mu x_{i}^{k} X_{i}^{k}=\sum_{j \in I_{\mathrm{pr}}} a_{i j}^{k} X_{j}^{k}+F_{i}^{k}+J_{i}^{k}+E N_{i}^{k}+\varepsilon x_{i}^{k} E X_{i}, & \quad i \in I_{\mathrm{pr}}, \\
\sum_{k=1}^{n} \mu n_{i}^{k} X_{i}^{k}-\sum_{k=1}^{n} E N_{i}^{k}=0, & i \in I_{\mathrm{pr}}, \\
J_{i}^{k}=\sum_{j=1}^{21} b_{i j}^{k} I_{j}^{k}, & i \in I_{\mathrm{pr}}, \\
Q_{j}^{k}=\left(1-\sum_{i \in I_{\mathrm{pr}}} a_{i j}^{k}\right) X_{j}^{k}, & j \in I_{\mathrm{pr}} .
\end{array}
$$


In (24) we have subdivided imports and exports of region $k$ into the national and international parts. In a realistic implementation of the production system balances a special study should be made of the international import and export patterns of individual sectors and regions. (25) balances out interregional shipment patterns. From (26) the investment delivery variables are linked to the investment consumption variables within region $k$. A fixed relationship between gross production and value added is introduced through eq. (27). Thus, we may move freely between gross production and value added in our model.

Summing (24)-(27) over regions yields the following expressions [(25) cancels out]:

$$
\begin{aligned}
& \bar{X}_{i}+\overline{I M}_{i}=\sum_{k=1}^{n} \sum_{j \in I_{\mathrm{pr}}} a_{i j}^{k} X_{j}^{k}+\sum_{k=1}^{n} F_{i}^{k}+\sum_{k=1}^{n} J_{i}^{k}+\overline{E X}_{i}, \\
& \sum_{k=1}^{n} J_{i}^{k}=\sum_{k=1}^{n} \sum_{j=1}^{21} b_{i j}^{k} I_{j}^{k}, \quad i \in I_{\mathrm{pr}}, \\
& \sum_{k=1}^{n} Q_{j}^{k}=\sum_{k=1}^{n}\left(1-\sum_{i \in I_{\mathrm{pr}}} a_{i j}^{k}\right) X_{j}^{k}, \quad j \in I_{\mathrm{pr}},
\end{aligned}
$$

(28)-(30) show that in general the value added restrictions (11) are not enough to ascertain consistency between the current model and a national level model. A necessary condition for such a consistency to hold is that the input-output coefficients $a_{i j}^{k}$ are independent of $k$. As shown, e.g., by Snickars (1978) this is not generally a reasonable assumption. Differences in detailed sectoral structures tend to introduce clear technological differences at the rather aggregate sectoral level employed here.

Under the above assumption only total consumption deliveries and total investment deliveries remain variable. However, as may be gathered from (29) it is also necessary to assume the investment distribution matrices $b_{i j}^{k}$ to be independent of $k$ for investment cost minimization in receiving sectors to be equivalent to consumption maximization.

By summing (28) and (29) over private sectors we obtain the results

$$
F_{\mathrm{pr}}+F_{\mathrm{pu}}+I_{\mathrm{pr}}+I_{\mathrm{pu}}=\sum_{i=1}^{21}\left(\bar{Q}_{i}+\overline{I M}_{i}-\overline{E X}_{i}\right),
$$




$$
\sum_{i=1}^{21} \sum_{k=1}^{n} J_{i}^{k}=\sum_{j=1}^{21} \sum_{k=1}^{n} I_{j}^{k},
$$

under the additional assumption that (11) holds with equality.

To complete the role of the input-output relationships in the model, income formation equations should be introduced to tie e.g., the public consumption to the public sector employment. Assuming that all public consumption is transformed to real wage-sums we would have the identity.

$$
\sum_{i \in I_{\mathrm{pr}}} F_{\mathrm{pui}}^{k}=\sum_{j \in I_{\mathrm{pu}}} w_{j}^{k} L_{j}^{k}
$$

Eq. (33) provides a means of keeping track of the resource redirections necessary within the economy pertaining to an increase, for instance, in the service standards for public child care. This modelling of income formation and distribution is an important field for further development in the current model.

\subsection{Objectives}

So far we have developed a system of restrictions that may be imposed on the regional development either from a technological or a regional policy perspective. We have done this in a one-period setting although the system as such might also be conceived of as operating at successive points in time. The connections between points of time are provided by the capital and investment relations (4)-(5). In the discussion below, we will not elaborate on the dynamics of the process modelled, but discuss criteria for the optimal choice among feasible solutions to the system of restrictions.

First of all we would like to make a distinction between two modes of usage of the model. In one instance it might be employed as a planning tool, to aid in tracing the effects of various regional policy measures on efficiency or welfare criteria. In the second mode the model may be employed as a forecasting device, imposing the full set of restrictions on a forecast of a likely regional development derived by information-theoretical principles. Below we shall make a subdivision of our arguments along these lines.

\subsubsection{Planning criteria}

Regional planning is a definitely multiobjective process. We have argued above that some of these objectives should be formulated as restrictions, since they are very often conceived that way in the political discussions. However, a programming model of the type described here might also be used to trace out trade-offs between objectives formulated as maximization 
or minimization criteria. These criteria may be linear or nonlinear, depending on the most appropriate specification to represent the aspect at hand, see Lundqvist (1980) for a further discussion on these matters.

The most straightforward planning criterion used in the tradition of regional economic models of partial equilibrium type, like the one we have developed, is to apply investment cost minimization to the system of restrictions. The main question that may be answered by this approach is by how much the room for consumption may be increased at the total national level by a wise regional distribution of resources both in the private and the public sector.

Thus, the basic objective function used in the model is

$$
\min I=I_{\mathrm{pr}}+\pi I_{\mathrm{pu}}=\sum_{i=1}^{21} \sum_{k=1}^{n} \alpha_{i}^{k} I_{i}^{k}+\pi \sum_{i=1}^{21} \sum_{k=1}^{n}\left(1-\alpha_{i}^{k}\right) I_{i}^{k} .
$$

In (34) $\alpha_{i}^{k}$ denotes the portion of investments in sector $i$, region $k$ that may be regarded as private and $\pi$ stands for a marginal rate of substitution parameter. Total investments are thus subdivided into a private part, $I_{\mathrm{pr}}$, and a public one, $I_{\mathrm{pu}}$, in criterion (34).

The most straightforward case in using objective (34) is to set $\pi=1$. Then the model becomes a standard cost minimization model; if $\pi=0$ is considered this implies that public sector investment costs are disregarded in the objective, although the system of restrictions imposes a demand for such investments to allocate private investments efficiently. This might possibly be seen as a description of investment behavior in the private sector. On the other hand $\pi \rightarrow \infty$ implies that no notice is taken of private investment costs. Such a behavior might characterize a public sector planning body which is very ill-informed about regional differentials in the productivity of new, private capital.

In this discussion of planning criteria we have focused on the trade-offs between different types of investment. One might of course also study other types of trade-offs, by formulating appropriate criteria, e.g.,

- maximize employment and/or participation rates,

- minimize income differentials between regions,

- minimize public service standard differentials between regions.

The current modelling set-up should prove useful in policy evaluations in a multiobjective framework. It goes without saying that these policy evaluations also contain variations of population and labour targets such as those in restrictions (14)-(16), or service standards such as those imposed in eqs. (17)(23). 


\subsubsection{Forecasting modes}

Suppose that we wish to derive the most probable distribution of capital stocks and population - in an information-theoretical sense - given that we have current observations of these distributions. Suppose further that we are given different pieces of information at the macro level of the future distribution. Such information may for example be summarized in the system of restrictions (1)-(39). A number of researchers, e.g., Snickars and Weibull (1977), Hårsman and Marksjö (1977) and Raquillet, Willekens and Por (1979), have suggested that an extended entropy measure is suitable in situations where conservative use is to be made of information added to current a priori knowledge in order to arrive at the most probable a posteriori distribution consistent with the available information.

In the current case an information-measure may be formulated as

$$
D_{c}\left\{(C, P) ;\left(C_{0}, P_{0}\right)\right\}=\sum_{i=k}^{21} \sum_{k=1}^{n} C_{i}^{k} \log \frac{C_{i}^{k}}{C_{0 i}^{k}}+\sum_{k=1}^{n} P^{k} \log \frac{P^{k}}{P_{0}^{k}} .
$$

A forecast might be made by minimizing (35) subject to (1)-(23) plus, possibly, the additional restriction that $I \geqq \bar{I}$, i.e., that total investments should not fall below $\bar{I}$. This forecast rests on the assumption that both capital and population are inert stocks, which are regionally mobile only in a rather long time perspective.

A variant of (35) is obtained by assuming that labour market inertia is more significant than capital inertia leading to the objective (36):

$$
D_{l}\left\{(L, P) ;\left(L_{0}, P_{0}\right)\right\}=\sum_{i=1}^{21} \sum_{k=1}^{n} L_{i}^{k} \log \frac{L_{i}^{k}}{L_{0 i}^{k}}+\sum_{k=1}^{n} P^{k} \log \frac{P^{k}}{P_{0}^{k}} .
$$

Note that since $L_{i}^{k}=C_{i}^{k} / \lambda_{i}^{l}$; the first term in (36) becomes

$$
\sum_{i=1}^{21} \sum_{k=1}^{n} C_{i}^{k} \log \frac{C_{i}^{k}}{C_{0 i}^{k}} \frac{1}{\lambda_{i}^{k}}
$$

From the above expression we see that (36) reduces the importance of sectors with a high capital-labour ratio in comparison with (35).

If there is reason to believe in strong stability patterns in gross migration patterns one might introduce the relations (16) in the restrictions (1)-(33) and change the second term in (36) for instance into (37),

$$
\sum_{k=1}^{n} M^{k} \log \frac{M^{k}}{M_{0}^{k}}+\sum_{k=1}^{n} U^{k} \log \frac{U^{k}}{U_{0}^{k}}
$$


By changing the composition of the variable mix of the informationadding measure (35), different forecasting schemes may thus be developed according to the hypotheses of stability and inertia at hand. ${ }^{4}$

In the following we shall give a few examples of applications of the types of analyses described above by using a 21-sector, 8-region model of the Swedish regional economic system. The idea is not to evaluate suggested regional policies, or to provide full-fledged forecasts, but to gain some insight in the qualitative aspects of the regional development process through an application of our model system to Swedish data for the period 1977-1983.

\section{Some planning and forecasting applications}

A mathematical model as the one described above can be used for a multitude of planning and forecasting applications. They may concern comprehensive issues as whether there exist trade-offs between national economic growth and low production factor mobility. Another type of planning application concerns ex ante evaluations of policy effects. Using a mathematical model enables the analyst to discern the direct and indirect effects of combined public policies. It is thus possible to anticipate the outcome of a proposed policy before implementing it in full scale. Negative interaction effects between combined policies may also be evaluated.

Short- or medium-term regional economic forecasts are often made by econometric models. They make use of time-series data for interdependent economic processes to project development patterns for population, employment and production, see e.g., Bolton (1980). A considerable amount of effort must usually be devoted to calibrating these models to yield consistent results.

The current model may be looked upon as an alternative outlook on the forecasting problem. We propose to use an optimization model for forecasting purposes. The basic idea is to use existing partial information, quantitative and qualitative, to constrain the future development alternatives and then to apply a paradigm of unbiasedness for the choice of trajectory among the feasible ones. Thus, if there exists an initial forecast, econometric or more rudimentary, and that trajectory is also feasible it will be accepted. If it is not feasible it will be corrected to the most likely one among the ones fulfilling all restrictions, see also Snickars and Weibull (1977).

In the sequel we will give some examples of the use of the REGAL model for applications of the type discussed above. We will focus on public and private sector interactions.

\footnotetext{
${ }^{4}$ In principle one could also adopt the same technique for interregional gross export patterns, both for the totals and for the intersectoral-interregional shipment flows.
} 


\subsection{Planning applications}

In the current application we have used three fundamental criteria, each having three components, i.e.,

- investments (total, private and public),

- capital stock mobility (total, private and public),

- employment mobility (total, private and public).

These objectives have been measured according to the expressions in formulas (34), (35) and (36). However, in (35) and (36) the expression (37) has been used throughout with $U^{k}=U_{0}^{k}$, i.e., the adjustment necessary of the population development to give labour market balance is supposed to affect the gross in-migration volumes to the various regions. This assumption is consistent with the multiregional demographic models of Rogers and Willekens (1978).

Using these nine objective functions we have investigated the room for increasing the national consumption level by distributing capital, employment and population efficiently over regions. ${ }^{5}$ The data used for the applications concerns the development in Sweden 1977-1983. A considerable amount of work has been devoted to assembling the data base. Special efforts have had to be made concerning regional capital stock and capital depreciation data. The reason for the choice of the period 1977-1983 for our applied analysis is that the estimations have been as far as possible made consistent with the data and results of the macroeconomic models at the national level used in the 1978 Long Term Economic Report of Sweden, see SOU $1978: 78$.

The results of the analyses of trade-offs are summarized in fig. 2 as regards some pair-wise trade-offs. A pay-off table with five-dimensional substitution effects is given in table 2 .

A major aim of the current modelling work has been to use realistic data and a set of rather simple supply-demand balances to analyze interrelations between the public and the private sector. Our basic result in this respect is shown in part (e) of fig. 2. This shows that there is in fact a considerable span in private investment costs depending on the criterion used to allocate these investments regionally. The span is five times bigger for private than for public investment costs. The main reason for this difference is that private investments are allocated according to comparative advantages whereas public investments are allocated according to self-sufficiency criteria.

An inspection of part (d) of fig. 2 corroborates this observation. A minimization of the mobility of public capital enforces a considerable reallocation of private capital. The reverse does not hold equally strongly.

Parts (a), (b) and (c) of fig. 2 show the two-dimensional transformation

${ }^{5}$ In the numerical examples restrictions (24)-(33) have not been used. 

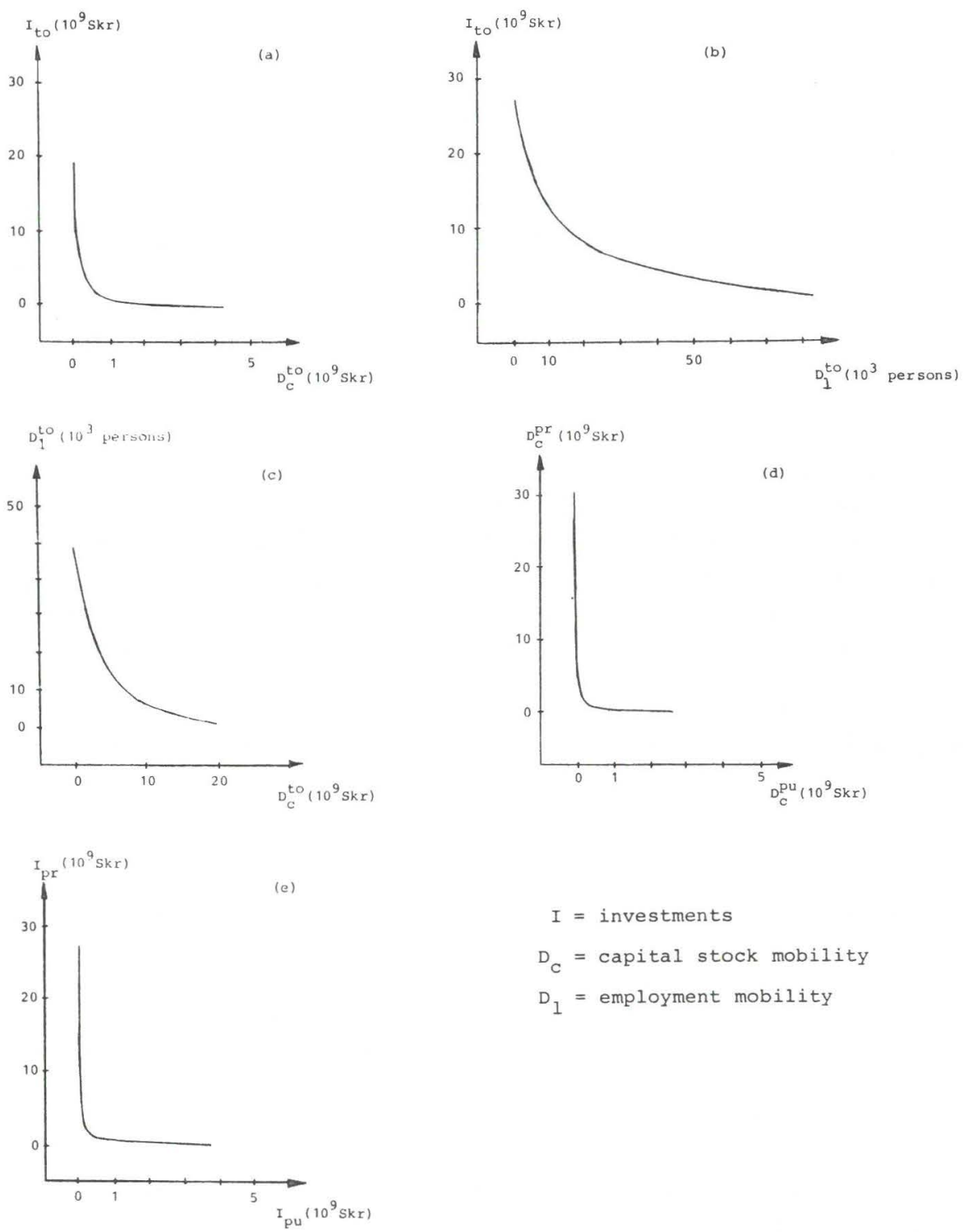

$$
\begin{aligned}
I & =\text { investments } \\
D_{C} & =\text { capital stock mobility } \\
D_{1} & =\text { employment mobility }
\end{aligned}
$$

Fig. 2. Transformation curves between various objective functions. 
Table 2

Pay-off matrix for five selected criteria. Minimal values scaled to zero.

\begin{tabular}{lcccll}
\hline & \multicolumn{3}{l}{ Minimisation of } & & \\
\cline { 2 - 6 } $\begin{array}{l}\text { Evaluation } \\
\text { in terms of }\end{array}$ & $\begin{array}{l}\text { Total } \\
\text { investments }\end{array}$ & $\begin{array}{l}\text { Private } \\
\text { investments }\end{array}$ & $\begin{array}{l}\text { Public } \\
\text { investments }\end{array}$ & $\begin{array}{l}\text { Capital } \\
\text { stock } \\
\text { mobility }\end{array}$ & $\begin{array}{l}\text { Employment } \\
\text { mobility }\end{array}$ \\
\hline $\begin{array}{c}\text { Total investments } \\
\left.\left(10^{9}\right) \text { Skr }\right)\end{array}$ & 0 & 2.5 & 28.0 & 4.0 & 27.0 \\
$\begin{array}{c}\text { Private investments } \\
\left(10^{9} \mathrm{Skr}\right)\end{array}$ & 1.0 & 0 & 27.0 & 5.0 & 28.5 \\
$\begin{array}{c}\text { Public investments } \\
\left(10^{9} \mathrm{Skr}\right)\end{array}$ & 1.0 & 4.0 & 0 & 1.0 & 0.5 \\
$\begin{array}{c}\text { Capital stock mobility } \\
\left(10^{9} \mathrm{Skr}\right)\end{array}$ & 20.0 & 42.0 & 58.0 & 0 & 20.0 \\
$\begin{array}{c}\text { Employment mobility } \\
\left(10^{3} \text { persons }\right)\end{array}$ & 92.5 & 176.0 & 272.0 & 48.5 & 0 \\
\hline
\end{tabular}

curves between total investments, total capital stock mobility and total employment mobility. It is quite clear from these three curves that low mobility has a cost in terms of room for consumption. The cost is somewhat bigger for low employment mobility than for low capital stock mobility. Also, the trade-off is more smooth between investment costs and employment mobility than between total investments and capital stock mobility. This is clearly seen from part (c) of fig. 2 .

The analysis thus shows that increased capital, labour and population mobility would lead to a larger room for total private and public consumption. Mobility seems to incur growth. On the other hand, our results indicate that there is a considerable degree of substitution between capital and labour mobility. It is not self-evident that the mobility of one or the other factor of production should be given all attention.

Table 2 spells out these results in a more comprehensive way. Public investments are seen to be quite stable, regardless of the allocation criterion. Capital stock mobility is equally much in opposition with employment mobility as with total investments.

In the literature on multiobjective decision methods, see e.g., Rietveld (1980), examples are given of methods to derive compromise solutions to the regional investment distribution problem. In our case this statement of the problem would amount to finding a compromise between a large room for consumption and a low mobility of population and labour. The usefulness of searching for a compromise involving capital stock mobility in a welfare perspective depends on the welfare losses attributable to high capital mobility.

Turning to the use of the REGAL model for policy evaluations, we will 
show its ability in determining the direct and total effects in employment and investment cost terms of levelling out the standards of child care in various regions. This is a typical situation not only in regional planning but also in other fields of public planning where policy options are weighed against one another.

Although we argued above that composite effects of several policies might be disentangled by our model evaluations we will not dwell on this problem here. Instead we will focus on comparing different norms or evaluation criteria in assessing the cost and other implications of a proposed policy.

In table 3 we show the results of a raise of the service provision parameters for child care and primary education to the level of the best equipped region (which is Upper North Sweden). Two evaluation criteria are compared, i.e., total investment cost minimization and minimization of total employment and population (gross inmigration) mobility.

The starting point of the evaluation is the reference case for the child care sector. This reference point may of course differ depending on the evaluation norm. Both methods yield the same direct employment and cost effects but slightly different indirect and induced effects. The employment multipliers are 1.38 and 1.40 whereas the investment cost multipliers are 1.12 and 1.14 . The results are therefore insensitive to the choice of evaluation norm.

The above test has shown that the raise in public sector standards has an impact also in the private part of the economy. This is both an indirect effect through intersectoral linkages and an induced effect through income changes (although the latter are very cruedly modelled).

Two further examples of public-private sector relations will be given here. The first one concerns the technological relationships between the private sectors and the public infrastructure sector. Since this sector is basically an energy sector a uniform raise in the infrastructure standards over regions implicitly implies that no change in the energy systems that would alter the regional self-sufficiencies are foreseen. If new energy systems, as for instance

Table 3

Direct and total employment and investment cost effects of a leveling out of standards of primary education. Comparison of evaluation criteria.

\begin{tabular}{|c|c|c|c|c|c|c|}
\hline \multirow[b]{2}{*}{ Norm of comparison } & \multicolumn{3}{|c|}{$\begin{array}{l}\text { Employment effect } \\
\text { (1,000 employed) }\end{array}$} & \multicolumn{3}{|c|}{$\begin{array}{l}\text { Investment effect } \\
\left(10^{9} \mathrm{Skr}\right)\end{array}$} \\
\hline & $\begin{array}{l}\text { Starting } \\
\text { point }\end{array}$ & Direct & Total & $\begin{array}{l}\text { Starting } \\
\text { point }\end{array}$ & Direct & Total \\
\hline $\begin{array}{l}\text { Investment cost } \\
\text { minimization }\end{array}$ & 372.0 & +67.6 & +93.5 & 17.4 & +9.5 & +10.6 \\
\hline $\begin{array}{l}\text { Employment mobility } \\
\text { minimization }\end{array}$ & 371.8 & +67.6 & +94.5 & 17.4 & +9.5 & +10.8 \\
\hline
\end{tabular}


nuclear power stations, are phased into the system, the uniform raise in standards would mean that scale and location economies in these investments are not fully considered.

To illustrate the effect of this change in technology we have not increased the $v$-parameters for sector 14 (public infrastructure) but imposed a claim for an increased national capital stock only. The additional capacity will then be distributed over regions according to the theory of comparative advantages. In our case the sensitivity test implies a shift of public infrastructure investment from Upper North Sweden to East Central Sweden and a replacement of these investments in the far north by equipment industry investments. This tends to increase the employment in Upper North Sweden by as much as 2 percent.

In the reference alternative the population levels of Southern Sweden and Western Sweden are both at their lower limits. We have investigated the effects of a lowering of that limit in Western Sweden by 50,000 persons (3 percent) and increasing it by the same amount in Southern Sweden. That change makes the employment drop in Western Sweden so that the participation rate is maintained. In Southern Sweden it raises the participation rate from 51.6 percent to 51.9 , which implies a participation rate among the extra in-migrants of 60 percent. Two thirds of the 30,000 new jobs created in Southern Sweden fall in the private sector. This type of information should be useful, and readily understandable, to local and regional level planning bodies.

\subsection{Forecasting applications}

We have argued for a clear distinction to be made between using a goaldriven mathematical model for policy and forecasting purposes. In spite of this we have used objectives related to capital stock or employment inertia for policy evaluations although such performance indicators have no clear policy connotation in themselves. Above we have motivated the use of these indicators by information theoretic arguments concerning an efficient use of existing macro information. In this perspective a minimization of capital stock or employment inertia may be seen as combining in a crude way micro with macro information.

Thus, a priori forecasts of use of capital and labour may be made, for instance on the basis of micro models of the behaviour of firms, public sector organizations and households. Aggregation of results of these models to our regional and sectoral level would then amount to the a priori most likely situation in the regional economy. However, various macro restrictions, both in the supply and demand dimensions, may be present with which the microbased forecasts are not consistent. Then, the current forecasting methodology may be seen as a constrained equilibrium in a situation where price 
mechanisms are not enough to clear all markets, see also Snickars and Weibull (1977) and Los (1979).

The current application represents a case where very crude micromodels exist. These models in our case are simply inertia-based, i.e., no change of the current situation is assumed. The use of capital stock distributions, employment situations and inmigration schedules are examples of alternative micro models in our forecasting perspective. A judgment of which entities are the most appropriate should be made on comparisons of the descriptive capacities, using historical data. For such applications of the current methodology, see Gustafsson, Hårsman and Snickars (1978).

Here we will merely present two forecasting-oriented applications of the REGAL model. The first one concerns a comparison of the distribution of total gross investments over regions in Sweden during the period 1977-1983 under different criteria for allocation.

In fig 3 five alternatives are compared. The first gives a reference point in terms of the 1977 distribution of the capital stock. In view of the stability of public investment distributions in the REGAL model the graphs in fig. 3 may to a large extent be interpreted as variants for private investment distribution over regions. We see that the Stockholm region would get a high percentage share of gross investments if private investment cost minimization was the only objective. A comparison of alternative one and four in fig. 3 shows that the macro restrictions are such that it is not possible to arrive at the 1977 capital stock distribution over regions. It is also interesting to note that a minimization of employment mobility would lead to a total capital stock distribution more reminiscent of the 1977 one than if capital mobility is minimized.

Table 4 gives a summary of the main results of the REGAL model for forecasting the regional development of employment in Sweden 1977-1983. Four variants of our model are compared with official forecasts and the actual development 1977-1979. We note that the capital stock-oriented variants of REGAL forecasts yield rather similar results. They all deviate markedly from official forecasts and actual short-term development. The REGAL forecast using the criterion of minimizing employment mobility resembles the actual development. The build-up forecast made within the Swedish system of employment planning for 24 counties gives a more negative development picture for northern Sweden than both the former alternatives.

The break-down of the 1978 Long-Term Economic Report for Sweden is done for the same period as the REGAL alternatives. However, that forecast is made only for labour demand and no equilibrium situation is derived, see Snickars (1981). Generally speaking, however, it is the most natural one to compare to our forecasts. A good correspondence is obtained for northern Sweden. The similarities for southern Sweden are not equally pronounced. 

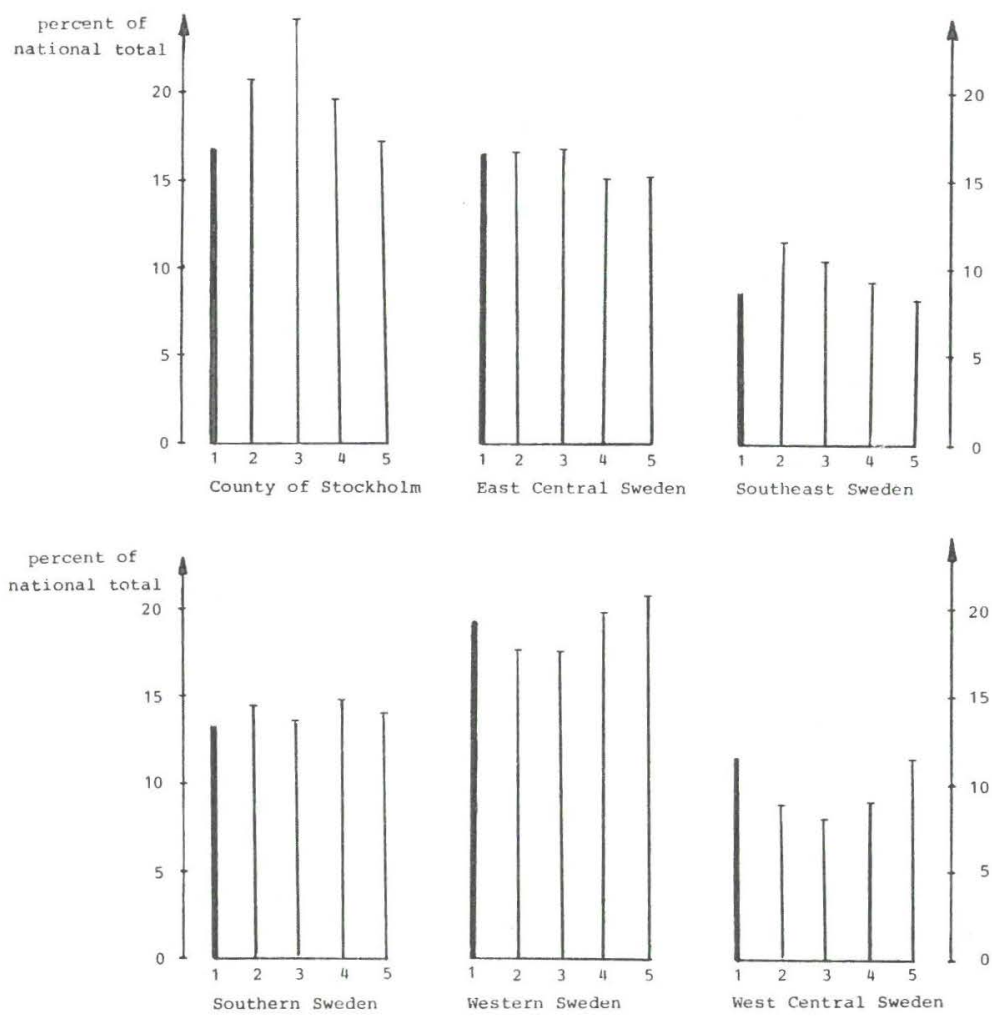

percent of
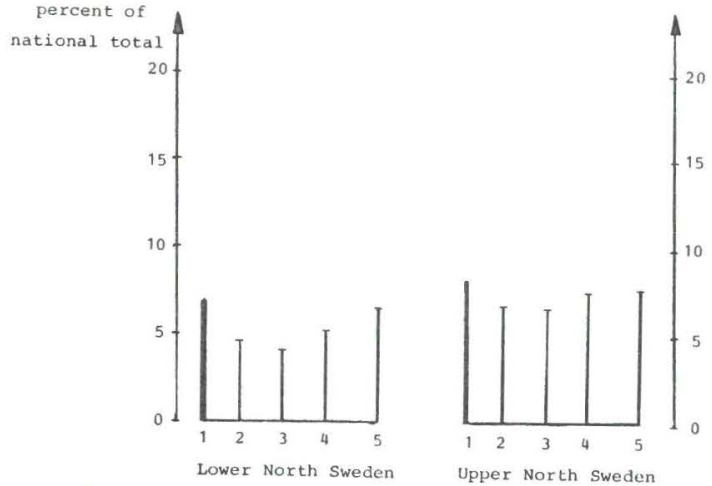

1. Capital stock distribution 1977

2. Total investment minimum

3. Private investment minimum

4. Total capital stock mobility minimum

5. Total employment mobility minimum

Fig. 3. Regional distribution of gross investments 1977-1983. 
Table 4

Employment growth (percent per year) in eight subregions of Sweden according to alternative forecasting criteria. Comparison with official forecasts 1977-1983.

\begin{tabular}{|c|c|c|c|c|c|c|c|c|c|}
\hline \multirow[b]{2}{*}{ Objective } & \multicolumn{9}{|l|}{ Region } \\
\hline & $\begin{array}{l}\text { County of } \\
\text { Stockholm }\end{array}$ & $\begin{array}{l}\text { East } \\
\text { Central } \\
\text { Sweden }\end{array}$ & $\begin{array}{l}\text { Southeast } \\
\text { Sweden }\end{array}$ & $\begin{array}{l}\text { Southern } \\
\text { Sweden }\end{array}$ & $\begin{array}{l}\text { Western } \\
\text { Sweden }\end{array}$ & $\begin{array}{l}\text { West } \\
\text { Central } \\
\text { Sweden }\end{array}$ & $\begin{array}{l}\text { Lower } \\
\text { North } \\
\text { Sweden }\end{array}$ & $\begin{array}{l}\text { Upper } \\
\text { North } \\
\text { Sweden }\end{array}$ & Sweden \\
\hline $\begin{array}{l}\text { Minimize total } \\
\text { investments }\end{array}$ & 3.0 & 0.2 & 2.4 & 1.1 & 0.3 & -0.3 & -0.4 & 0.0 & 1.1 \\
\hline $\begin{array}{l}\text { Minimize private } \\
\text { investments }\end{array}$ & 4.5 & 0.2 & 1.4 & 0.7 & 0.3 & -0.3 & -0.8 & 0.0 & 1.2 \\
\hline $\begin{array}{l}\text { Minimize } \\
\text { total capital } \\
\text { stock mobility }\end{array}$ & 2.6 & 0.2 & 1.3 & 1.4 & 0.9 & -0.3 & -0.2 & 1.0 & 1.1 \\
\hline $\begin{array}{l}\text { Minimize total } \\
\text { employment mobility }\end{array}$ & 1.5 & 0.7 & 0.4 & 1.1 & 1.3 & 0.6 & 0.9 & 1.1 & 1.0 \\
\hline $\begin{array}{l}\text { Breakdown of } \\
\text { forecast 1977-1983 } \\
\text { in } 1978 \text { Long Term } \\
\text { Report }\end{array}$ & 0.8 & 1.6 & 1.3 & 1.1 & 0.4 & 0.4 & 0.8 & 1.2 & 0.9 \\
\hline $\begin{array}{l}\text { County } \\
\text { planning } 1980 \\
1979-1985 \text { forecast }\end{array}$ & 1.1 & 0.6 & 0.3 & 0.7 & 0.4 & 0.3 & 0.2 & -0.2 & 0.5 \\
\hline $\begin{array}{l}\text { Actual } \\
\text { development } \\
\text { 1977-1979 }\end{array}$ & 1.4 & 1.0 & 0.3 & 0.9 & 0.6 & 1.2 & 0.8 & 1.7 & 1.0 \\
\hline
\end{tabular}


These forecasting comparisons are not aimed to be more than illustration of a mode of use of a mathematical programming model for forecasting purposes. Without going into details about the descriptive capacities we would argue that this is a useful tool especially for medium-term forecasting work.

\section{Some possible extensions}

There have been very few attempts to integrate the public sector into regional economic models. This paper has given an initial contribution to the modelling of some of the private and public sector interactions. We have treated three of the four roles of the public sector stated in the introduction and only hinted at some of the issues related to modelling the public sector as an income transfer agent. An extension of the model in the latter direction would seem most warranted.

Another extension of the model which also relates to the role of the public sector has to do with the treatment of excess capacities. Since we have assumed a fixed utilization of capital in our model we have no means for simulating cases where there is excess capacity in the public sector service and infrastructure provision. Such a property of the model would seem useful in a situation where secular decline coexists with regional growth.

A third line of extension, which is most important for the forecasting mode of use of the model, is to treat the time dimension more explicitly. This can be done by making the model as multiperiod one. However, such a development would introduce a stronger demarcation line between the planning and forecasting version of the REGAL model. In the planning version it would be natural to take recourse to dynamic optimization, deriving optimal development trajectories over several time-periods. In the forecasting version the time-dimension should instead be treated recursively.

The current model rests to a large extent on quite simple demand theory. It would be useful to increase the theoretical strength of some of the arguments for introducing our demand and supply functions for public services. The REGAL model is intended to have a practical appeal so that its structure and results can be understood by practical planners. The effort devoted to an increased theoretical complexity must therefore be weighed against the usefulness of the model for practical policy evaluation and forecasting work.

\section{Appendix: Mathematical description of the model and full notations}

\section{A.1. Variables (for the horizon year)}

$X_{i}^{k} \quad=$ gross production in sector $i$, region $k$,

$Q_{i}^{k} \quad=$ value added in sector $i$, region $k$, 
$L_{i}^{k} \quad=$ employment in sector $i$, region $k$,

$C_{i}^{k} \quad=$ capital stock in sector $i$, region $k$,

$P^{k} \quad=$ population in region $k$,

$M^{k} \quad=$ gross in-migration to region $k$ during planning period,

$U^{k} \quad=$ gross out-migration from region $k$ during planning period,

$L^{k} \quad=\sum_{i=1}^{21} L_{i}^{k}=$ total employment in region $k$,

$E N_{i}^{k} \quad=$ national exports from sector $i$, region $k$,

$F_{i}^{k} \quad=$ consumption deliveries from sector $i$ to region $k$,

$J_{i}^{k} \quad=$ investment deliveries from sector $i$ to region $k$,

$I_{i}^{k} \quad=$ gross investment made in sector $i$, region $k$,

$I_{\mathrm{pu}} \quad=$ investments in sector $1-3,5,13-14,17,21$,

$I_{\mathrm{pr}} \quad=$ investments in sector $4,6-12,15-16,18-20$,

$F_{\mathrm{pu}} \quad=$ consumption deliveries in sector $1-3,5,13-14,17,21$,

$F_{\mathrm{pr}} \quad=$ consumption deliveries in sector $4,6-12,15-16,18-20$.

\section{A.2. Exogenous constants}

$\bar{Q}_{i} \quad=$ forecast national production level in sector $i, i=4, \ldots, 12,16,18-20$,

$\bar{L}_{i} \quad=$ forecast national employment level in sector $i, i=1, \ldots, 5,15,17$,

$\bar{C}_{i} \quad=$ forecast national capital stock in sector $i, i=13,14,21$,

$\overline{E X}_{i}=$ total exports from sector $i$,

$\overline{I M}_{i} \quad=$ total imports to sector $i$,

$\bar{X}_{i} \quad=$ gross production in sector $i$,

$\underline{L}_{i}^{k} \quad=$ lower limits of employment levels in sector $i$, region $k, i=1, \ldots, 12$, $14, \ldots, 20$. For sectors $i=16, \ldots, 21$ the lower limits $\underline{L}_{i}^{k}$ are equalities, i.e., the regional distribution of the employment in these sectors is exogenously determined,

$\bar{P} \quad=$ forecast national population,

$\underline{P}^{k}, \bar{P}^{k}=$ lower and upper limits of regional population levels,

$\bar{C}_{0 i}^{k} \quad=$ initial capital stock in sector $i$, region $k$,

$P_{0}^{k} \quad=$ initial population in region $k$,

$L_{0 i}^{k} \quad=$ initial employment in sector $i$, region $k$,

$M_{0}^{k}, U_{0}^{k}=$ gross in- and out-migration in region $k$ in earlier time period.

\section{A.3. Parameters}

$\sigma_{i}^{k}=$ minimum requirement service level in sector $i$, region $k$,

$v_{j}^{k}=$ minimum requirement public infrastructure level in sector group $j$, region $k$ (special definition for $j=1$ ),

$\phi_{i}^{k} \quad=$ proportion of female employees in sector $i$, region $k$,

$\Psi^{k} \quad=$ natural growth of initial population in region $k$,

$\beta^{k} \quad=$ proportion of regional population of age less than 18 years in region $k$, 


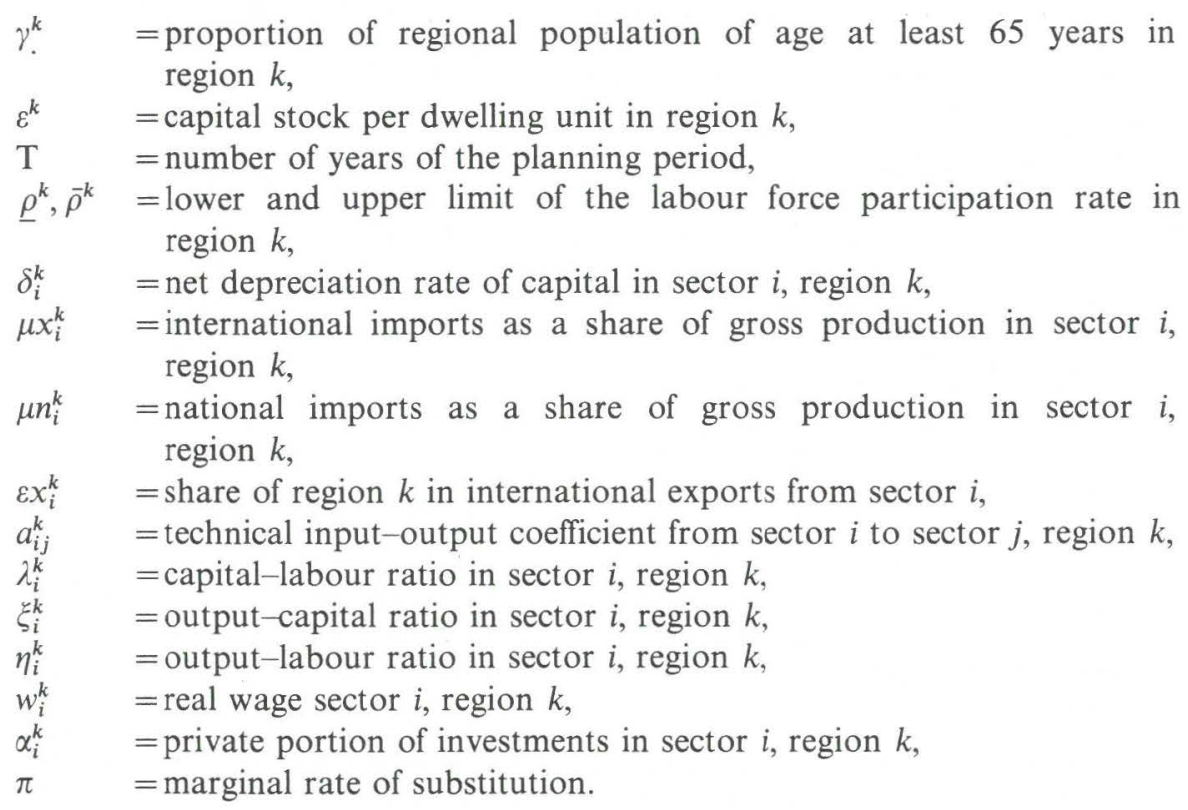

\section{References}

Andersson, Å.E. and H. Persson, 1980, Integration of transportation and location analysis: A general equilibrium approach, RR-80-40 (International Institute for Applied Systems Analysis, Laxenburg).

Ballard, K. and R. Wendling, 1980, The national-regional impact system: A spatial model of US economic and demographic activity, Journal of Regional Science, May.

Batten, D., 1980, Interregional linkages between national and regional input-output models, Research Report (University of Gothenburg, Gothenburg).

Bolton, R., 1980, Multiregional models in policy analysis: A survey, RP-30 (Department of Economics, Williams College, Williamstown, MA).

Carlberg, M., 1979, A multiregional input/output forecasting model - the case of West Germany, Paper presented at the European Congress of the Regional Science Association (Fribourg).

Courbis, R., 1979, The REGINA model: A regional-national model for French planning, Regional Science and Urban Economics 9.

Courbis, R. and G. Cornilleau, 1978, The REGIS model: A simplified version of the nationalregional REGINA model, Paper presented at the European Congress of the Regional Science Association (Fribourg).

Granholm, A., 1981, Interregional planning models for the allocation of private and public investments, Ph.D. dissertation (Department of Economics, University of Gothenburg, Gothenburg).

Granholm, A. and O. Ohlsson, 1975, A note on distribution analysis in linear programming models, Regional Science and Urban Economics 5.

Gustaffson, J., B. Hårsman and F. Snickars, 1978, Medium term forecasting models for the housing market - the Stockholm case, Papers of the Regional Science Association, Vol. 40.

Hårsman, B. and B. Marksjö, 1977, Modelling household changes by efficient informationadding, in A..E. Andersson and I. Holmberg, eds., Demographic, economic and social interaction (Ballinger, Boston, MA).

RSUE-F 
Karlqvist, A., R. Sharpe, D. Batten and J. Brotchie, 1978, A regional planning model and its application to southeastern Australia, Regional Science and Urban Economics 8.

Los, M., 1979, Discrete choice modelling and disequilibrium in land-use and transportation planning, Publication 137 (Centre de Recherche sur les transports, Université de Montréal, Montréal).

Los, M., 1980, A transportation-oriented multiregional economic model for Canada, Research Paper 178 (Centre de Recherche sur les Transports, Université de Montréal, Montréal).

Lundqvist, L., 1977, Planning for freedom of action, in: A. Karlqvist, L. Lundqvist, F. Snickars and J.W. Weibull, eds., Spatial interaction theory and planning models (North-Holland, Amsterdam).

Lundqvist, L., 1980. A dynamic, multiregional input-output model for analyzing regional development, employment and energy use, Paper presented at the European Congress of the Regional Science Association (Munich).

Martellato, D., 1980, Structural analysis with an updated interregional input-output model for Italy 1977, Paper presented at the European Congress of the Regional Science Association (Munich).

Mennes, L.B.M., J. Tinbergen and J.G. Waardenburg, 1969, The element of space in development planning (North-Holland, Amsterdam).

Ohlsson, O., A. Granholm et al., 1972, Regionalekonomiska modeller med tillämpning på stockholmsregionen (Stockholms generalplaneberedning, Stockholm).

Polenske, K., 1972, The implementation of a multiregional input-output model for the United States, in: A. Brody and A. Carter, eds., Input-output techniques (North-Holland Amsterdam).

Raquillet, R., F. Willekens and A. Por, 1979, Entropy, multiproportional and quadratic techniques for inferring detailed migration patterns from aggregate data, mathematical theories, algorithms, application and computer programs, WP-79-88 (International Institute for Applied Systems Analysis, Laxenburg).

Rietveld, P., 1980, Multiple objective decision methods and regional planning (North-Holland, Amsterdam)

Rogers, A. and F. Willekens, 1978, Spatial population analysis: methods and computer programs, RR-78-18 (International Institute for Applied Systems Analysis, Laxenburg).

Snickars, F., 1978, Construction of interregional input-output tables by efficient informationadding, in: R. Ketellapper and C. Bartels, eds., Exploratory and explanatory regional analysis of statistical data (Nijhoff, Leiden).

-Snickars, F., 1981, Regional development consequences of closing down Swedish nuclear power, WP-81-00 (International Institute for Applied Systems Analysis, Laxenburg).

Snickars, F. and L. Lundqvist, 1978, Investments and transports in interdependent regions - a dynamic regional model, in: W. Buhr, P. Friedrich, Competition among small regions (Nomos, Baden-Baden).

Snickars, F. and J.W. Weilbull, 1977, A minimum information principle: theory and practice Regional Science and Urban Economics 7.

SOU 1978: 78, 1978, Långtidsutredningen 1978, Huvudrapport (Liber Förlag, Stockholm).

Thys-Clement, F., P. van Rompuy and L. de Corel, 1979, RENA, a regional model for Belgium, in: R. Courbis, ed., Modèles régionaux et modèles régionaux-nationaux (CUJAS, Paris).

Treytz, G., 1980, Design of a multiregional policy analysis model, Journal of Regional Science, May.

Williams, H.W.C.L. and M.L. Senior, 1977, Accessibility, spatial interaction and the spatial benefit analysis of land use-transportation plans, in: A. Karlqvist, L. Lundqvist, F. Snickars and J.W. Weibull, eds., Spatial interaction theory and planning models (North-Holland, Amsterdam). 